\title{
COMUNICAÇÃO
}

\section{SELEÇÃO PARA ALTO TEOR DE ACILAÇÚCARES EM GENÓTIPOS DE TOMATEIRO E SUA RELAÇÃO COM A RESISTÊNCIA AO ÁCARO VERMELHO (Tetranychus evansi) E À TRAÇA (Tuta absoluta)}

\author{
Selection towards high acylsugar levels in tomato genotypes and its relationship with resistance \\ to spider mite (Tetranychus evansi) and to the South American pinworm (Tuta absoluta)
}

\author{
Guilherme Victor Nippes Pereira ${ }^{1}$, Wilson Roberto Maluf ${ }^{3}$, Luciano Donizete Gonçalves ${ }^{2}$, \\ Ildon Rodrigues do Nascimento ${ }^{4}$, Luís Antônio Augusto Gomes ${ }^{5}$, Vicente Licursi ${ }^{6}$
}

\begin{abstract}
RESUMO
Uma das estratégias do melhoramento do tomateiro, no Brasil, visando à resistência a pragas, tem sido a utilização de aleloquímicos presentes nos folíolos. Objetivou-se no presente trabalho, estudar os níveis de resistência a dois artrópodos-pragas [traça do tomateiro (Tuta absoluta) e ácaros (Tetranychus evansi)], em genótipos previamente selecionados com base apenas no seu teor foliar de acilaçúcares. Foram selecionadas 11 plantas contrastantes quanto aos níveis de acilaçúcares nos folíolos, de uma população $\mathrm{F}_{3} \mathrm{RC}_{2}$, derivada do cruzamento interespecífico Lycopersicon esculentum Mill 'TOM-584' x Lycopersicon pennellii (Correll) D'Arcy 'LA-716'. Esses genótipos, juntamente com os genitores TOM-584 e LA-716, foram submetidos a ensaios de repelência/resistência a artrópodos-pragas. No teste de repelência ao ácaro T. evansi, as plantas com altos teores de acilaçúcares se comportaram de forma semelhante ao genitor resistente LA-716. As magnitudes das correlações foram negativas e significativas, confirmando assim a associação entre altos teores do aleloquímico e a resistência (repelência) ao ácaro, avaliada pela distância percorrida. No ensaio realizado com a traça do tomateiro, os genótipos foram avaliados para danos nas plantas e lesões nos folíolos. Os genótipos contendo alto teor de acilaçúcares, demonstraram bons níveis de resistência a Tuta absoluta, não diferindo significativamente do acesso selvagem LA-716. Em todas as épocas de avaliação, os teores de acilaçúcares mostraram-se alta e negativamente correlacionados com os níveis de dano causados pela traça. Os resultados obtidos comprovaram a eficiência da seleção de genótipos de tomateiro com elevados teores de acilaçúcares nos folíolos, visando à resistência a artrópodos-praga.
\end{abstract}

Termos para indexação: Melhoramento do tomateiro, acilaçúcares, traça do tomateiro, ácaro.

\begin{abstract}
Selection for high foliar levels of allelochemicals has been proposed as a suitable strategy for breeding tomatoes for arthropod pest resistance. In the Lycopersicon pennellii (Correll) D'Arcy accession LA-716, acylsugars exsudated by type IV glandular trichomes present in all aerial parts of the plant reportedly mediate resistance to arthropod pests. This paper intended to study the levels of resistance to two arthropod pests, the South American tomato pinworm (Tuta absoluta) and spider mites (Tetranychus evansi) in tomato genotypes selected solely on the basis of their foliar acylsugar contents. Eleven plants with contrasting acylsugar contents were selected from population $\mathrm{F}_{3} \mathrm{BC}_{2}$ derived from the interespecific cross Lycopersicon esculentum 'TOM-584'x Lycopersicon pennellii 'LA-716'. These genotypes were used in tests for resistance/ repellence to the arthropod pests, along with parental checks TOM-584 and LA-716. In Tetranychus spp. mite repellence tests, plants selected for high acylsugar contents behaved similarly to the resistant parent LA-716. Negative and significative correlations between acylsugar contents and distances travelled by the mites onto the leaflet surface indicated an association between the allelochemical and the levels of mite repellence. In the assay with the South American pinworm, these genotypes were evaluated for leaflet lesion type and overall plant damage. The high acylsugar genotypes had good levels of insect resistance, similar to those found in LA-716. In all the evaluation date, acylsugars levels were highly and negatively correlated with pinworm damage. The results indicated that selection for high acylsugar contents was effective in increasing the levels of arthropod resistance of tomato genotypes.
\end{abstract}

Index terms: Tomato breeding, acylsugars, South American pinworm, spider mite.

(Recebido em 22 de novembro de 2005 e aprovado em 9 de outubro de 2006)

\footnotetext{
1Doutor - Centro de Ciências Biológicas e da Saúde - Universidade Estadual de Montes Claros/UNIMONTES - Cx. P. 126 - Montes Claros, MG - $39401-089$ guilherme.pereira@unimontes.br

2Mestre - Departamento de Agricultura/DAG - Universidade Federal de Lavras/UFLA - Cx. P. 3037-37200-000 - Lavras, MG - ludonizeti@yahoo.com.br ${ }^{3}$ Ph. D. - Departamento de Agricultura/DAG - Universidade Federal de Lavras/UFLA - Cx. P. 3037 - 37200-000 - Lavras, MG - wrmaluf@ufla.br ${ }^{4}$ Doutor - Departamento de Agronomia - CEDETEG - Rua Simeão Camargo Varela de Sá, 03 - Cx. P. 3010 - 85040-080 - Guarapuava, PR ildon_nascimento@yahoo.com.br

${ }^{5}$ Doutor - Departamento de Agricultura/DAG - Universidade Federal de Lavras/UFLA - Cx. P. 3037 - 37200-000 - Lavras, MG - laagomes@ufla.br ${ }^{6}$ Técnico Agrícola - ORTIAGRO - 37.205-000 - ljaci, MG - vicenteli@navinet.br
} 
O cultivo do tomateiro (Lycopersicon esculentum Mill.) é de grande importância econômica e social, pois ele é praticado em todos os estados do Brasil, especialmente nas regiões Sudeste e Centro-Oeste (FILGUEIRA, 2000).

A cultura do tomateiro angariou muitos ganhos genéticos com o melhoramento de plantas, sendo cultivada em vários países do mundo. Apesar disso, apresenta muitos problemas, principalmente fitossanitários (SILVA \& CASALI, 1979).

Durante a domesticação do tomateiro, houve perda de alelos importantes, principalmente para resistência a pragas e doenças, provocando um estreitamento na base genética, o que é um dos motivos para explicar a suscetibilidade das atuais cultivares a inúmeros patógenos e pragas. Uma das alternativas para a obtenção de uma melhor relação custo/benefício é o desenvolvimento de cultivares resistentes.

Os programas de melhoramento do tomateiro conduzidos no Brasil, visando à obtenção de cultivares resistentes a pragas, têm adotado a estratégia de incorporação de alelos de resistência de materiais selvagens, que contêm aleloquímicos associados à resistência - metilcetonas (2-tridecanona), sesquiterpenos (zingibereno) e acilaçúcares (ARAGÃO, 1998; BARBOSA, 1994; CAMPOS, 1999; FREITAS, 1999; GONÇALVES et al., 1998; GONÇALVES-GERVASIO, 1998; LABORY, 1996; PAMPLONA, 2001; RESENDE, 2003), em cultivares comerciais. Em geral, a seleção para alto teor dos aleloquímicos tem levado a respostas correlacionadas no sentido de aumentar a resistência à pragas. Em genótipos derivados de Lycopersicon pennellii (Correll) D'Arcy 'LA716', a resistência a pragas é atribuída à presença de acilaçúcares (AZEVEDO et al., 1999; GOFFREDA et al., 1988, 1989; PAMPLONA, 2001).

A herança dos teores dos acilaçúcares oriundos de Lycopersicon pennellii foi estabelecida por Lenke \& Mutschler (1984) e Resende et al. (2002) sendo considerada de efeito monogênico, onde o alelo recessivo é responsável por altos teores de acilaçúcares.

A traça do tomateiro [Tuta absoluta Meyrick 1917 (Lepidoptera: Gelechiidae)] é atualmente considerada uma das pragas mais importantes do tomateiro cultivado no Brasil. Ocorre durante todo ciclo da cultura, danificando folhas, ramos, caule, ponteiros, brotações, flores e frutos (BARBOSA \& SILVEIRA NETO, 1984). Elevadas populações desse inseto podem destruir até $90 \%$ da área foliar (LOURENÇÃO et al., 1984), com grandes perdas na produção (SOUZA \& REIS, 2000). Existem diversos tipos de controle da praga: controle cultural, controle bológico e controle químico que, de maneira isolada, não conseguem obter uma boa eficácia. A obtenção de cultivares comerciais com resistência genética é outro tipo de controle com grande potencial. Um dos projetos desenvolvidos com essa finalidade, é a seleção de tomateiros resistentes a artropodos-pragas, do Prof Wilson Roberto Maluf (UFLA) na qual a resistência é mediada por acilaçúcares.

Algumas espécies de ácaros são consideradas pragas importantes na cultura do tomateiro. Quando o índice de infestação nos folíolos excede 15\%, podem levar à perdas substanciais na produção (FLECHTMANN, 1989). Os danos causados pelo ácaro [Tetranychus evansi Baker \& Pritchard (Acari: Tetranychidae)] são diretos, ocasionando seca das folhas, seguida de desfolha, diminuição no tamanho e número de frutos, além de indução à maturação precoce (FLECHTMANN \& BAKER, 1970).

O controle cultural tem sido empregado no combate aos ácaros Tetranychus spp., porém, sem grande êxito em virtude da dificuldade de ser executado na prática, principalmente pela grande quantidade de plantas hospedeiras. O controle químico, com uso de acaricidas específicos, tem sido amplamente utilizado, porém, seus efeitos no ambiente têm sido consideravelmente questionados (BARBOSA \& FRANÇA, 1980; FLECHTMANN, 1989). O controle biológico de ácaros fitófagos também merece destaque, seja pelo uso de predadores, seja pelo uso de fungos entomopatógenos (TAMAI, 1997).

Aragão (1998) e Campos (1999), testaram a metodologia da resistência varietal em tomateiros oriundos de cruzamentos interespecíficos utilizando os aleloquímicos 2-tridecanona e zingibereno. Resende (2003) obteve correlação negativa e significativa entre elevados teores de acilaçúcares e a distância percorrida pelos ácaros em tomateiros selecionados para teores contrastantes de acilaçúcares, a partir do cruzamento interespecífico L. esculentum 'TOM-584' x L. pennellii 'LA-716'.

Assim, o presente trabalho objetivou estudar os níveis de resistência a dois artrópodos-pragas [traça do tomateiro (Tuta absoluta) e ácaro (Tetranychus evansi)], em genótipos previamente selecionados, com base apenas no seu teor foliar de acilaçúcares e correlacionar esses teores com a resistência.

A partir do cruzamento interespecífico Lycopersicon esculentum 'TOM-584' $\mathrm{x}$ Lycopersicon pennellii 'LA-716', foram realizados retrocruzamentos para a cultivar comercial. Posteriormente, as plantas da geração 
$\mathrm{F}_{3} \mathrm{RC}_{2}$ foram avaliadas quanto ao teor de acilaçúcares utilizando-se o método colorimétrico (RESENDE et al., 2002). Foram obtidas plantas com diversos teores de acilaçúcares, sendo selecionadas as que apresentaram teores semelhantes a LA-716 e a TOM-584 e elas foram utilizadas para os ensaios de resistência à traça do tomateiro e ao ácaro vermelho.

Para a realização do ensaio para resistência à traça, foram selecionadas seis plantas entre 400 plantas da população $\mathrm{F}_{3} \mathrm{RC}_{2}$ do cruzamento interespecífico de Lycopersicon esculentum 'TOM-584' e Lycopersicon pennellii 'LA-716', sendo quatro com alto teor de acilaçúcares (BPX-370E-30-380-68-6, BPX-370E-30-380-688, BPX-370E-30-275-11-7, BPX-370E-30-275-11-8) e duas com baixo teor (BPX-370E-30-380-27-7 e BPX-370E-25-27129-2). Essas plantas, juntamente com os genitores TOM584 e LA-716, utilizados como testemunhas, foram clonadas por estaquia e submetidas à infestação com a traça do tomateiro Tuta absoluta em gaiolas, em estufa, aos cinqüienta dias após a clonagem, no Departamento de Agricultura da UFLA.

O experimento foi conduzido de acordo com a metodologia utilizada por Barbosa (1994), em delineamento, em blocos, casualizados com 3 repetições, sendo que cada genótipo (planta) correspondia a uma parcela. Os genótipos foram avaliados em 4 épocas distintas (dias após a infestação - d.a.i.), sendo a primeira aos vinte dias após a infestação (março de 2004) e as demais a cada dez dias consecutivos (30, 40 e 50 dias após a infestação). Os genótipos foram avaliados com base em uma escala de notas, proposta por Barbosa (1994) e Labory (1996), para as características danos na planta aos 20 d.a.i, 30 d.a.i., 40 d.a.i. e 50 d.a.i.; lesões no folíolo aos 20 d.a.i., 30 d.a.i. e 40 d.a.i e porcentagem de folíolos atacados somente aos 50 d.a.i. As plantas foram avaliadas por 3 avaliadores independentes, tomando-se como nota final da avaliação a média das notas atribuídas pelos referidos avaliadores. Dez dias após a infestação, foi avaliada a ovoposição, mediante a contagem do número total de ovos das plantas.

As médias das notas dos três avaliadores, em cada época de avaliação, foram submetidas à análise de variância utilizando-se o teste de médias de Scott-Knott. Também foram realizados diversos contrastes de interesse entre os genótipos avaliados e as correlações entre os teores de acilaçúcares e os níveis de dano causados pela traça do tomateiro.

Para verificar a relação entre teor de acilaçúcares e e resistência ao ácaro Tetranychus evansi, foi realizado um bioteste utilizando-se a câmara fria da empresa HortiAgro
Sementes Ltda; no município de Ijací,MG, durante o mês de fevereiro de 2005. Os ácaros vermelhos foram coletados em plantas de tomateiro, oriundos de criação em gaiolas localizadas em estufa agrícola do Departamento de Agricultura da Universidade Federal de Lavras, tendo sido previamente submetidos à confirmação de classificação de espécie no Laboratório de Acarologia da Empresa de Pesquisa Agropecuária de Minas Gerais - EPAMIG Lavras, MG.

Tomaram-se nove genótipos da geração $\mathrm{F}_{3} \mathrm{RC}_{2}$ dos onze previamente selecionados com base nos teores contrastantes de acilaçúcares nos folíolos. Das nove plantas selecionadas, cinco apresentavam baixo teor (BPX370E-25-271-30-5, BPX-370E-25-271-30-8, BPX-370E-25-27179-7, BPX-370E-30-275-70-2 e BPX-370E-30-275-70-9) e quatro alto teor de acilaçúcares (BPX-370E-30-380-68-6, BPX-370E-30-380-68-8, BPX-370E-30-275-11-7 e BPX-370E30-275-11-8).

Esses genótipos foram clonados por estaquia e posteriormente utilizados nos testes de resistência (repelência) ao ácaro (Tetranychus evansi), juntamente com os genótipos parentais TOM-584 (testemunha suscetível, com baixo teor de acilaçúcares) e LA-716 (testemunha resistente, com alto teor de acilaçúcares), totalizando onze tratamentos.

A resistência ao ácaro Tetranychus evansi foi quantificada por meio do bioteste proposto por Weston \& Snyder (1989), em 3 repetições.

Após a transferência dos ácaros em cada tratamento, foram medidas as distâncias médias percorridas pelos ácaros (em mm) sobre a superfície de cada folíolo a partir do centro de tachinha após 20, 40 e 60 minutos. Foi considerada como zero a distância percorrida pelos ácaros que permaneceram sobre a tachinha e para aqueles que saíram do folíolo, foi considerada a distância do centro do folíolo até sua borda, no sentido longitudinal.

Este tipo de experimento estima a repelência de genótipos ao ácaro, sendo que, quanto menor a distância percorrida sobre os folíolos, maior a repelência da planta ao ácaro. Os dados do bioteste foram coletados individualmente para cada tempo de avaliação, sendo determinada a distância média percorrida pelos dez ácaros.

Os resultados da avaliação dos genótipos utilizados foram analisados por meio de uma análise de variância e por meio do teste de comparação de médias de Scott-Knott . Também foram realizados contrastes de interesse entre os genótipos avaliados e as correlações entre os níveis de acilaçúcares e as distâncias percorridas pelos ácaros. 
No experimento com a traça, na avaliação aos 20 dias após a infestação (d.a.i.), não se observaram diferenças significativas entre genótipos com relação às médias de danos nas plantas (Tabela 1). Contudo, aos 30 d.a.i. e aos 50 d.a.i., os genótipos da geração $\mathrm{F}_{3} \mathrm{RC}_{2}$ selecionados para alto teor de acilaçúcares, não diferiram estatisticamente pelo teste de Scott-Knott $(\mathrm{a}=0,05)$ do genitor selvagem LA-716 quanto às médias de danos nas plantas (Tabela 1), demonstrando bons níveis de resistência à Tuta absoluta diferindo no entanto com relação aos genótipos selecionados para baixos teores e com relação ao TOM-584.

Esses mesmos genótipos apresentaram-se superiores aos demais genótipos selecionados para baixo teor de acilaçúcares com relação às notas de lesões nos folíolos nas avaliações efetuadas aos 30 e 40 d.a.i. não tendo as notas médias de lesões nos folíolos dos genótipos citados, diferido significativamente das do genitor LA-716 (Tabela 2).

Tabela 1 - Notas médias de danos nas plantas, suas correlações e estimativas de contrastes de interesse de 8 genótipos de tomateiro selecionados para teores extremos de acilaçúcares sob infestação da traça do tomateiro Tuta absoluta. UFLA, Lavras, MG, 2004.

\begin{tabular}{|c|c|c|c|c|c|}
\hline \multirow[t]{2}{*}{ Genótipos } & \multicolumn{5}{|c|}{$\begin{array}{c}\text { Danos nas plantas } \\
\text { Dias após infestação (d.a.i.) }\end{array}$} \\
\hline & 20 d.a.i. & 30 d.a.i. & 40 d.a.i. & \multicolumn{2}{|l|}{50 d.a.i. } \\
\hline LA-716 & $0,66^{11} \mathrm{a}$ & $1,22 \mathrm{a}$ & $1,33 \mathrm{a}$ & \multicolumn{2}{|c|}{$1,11 \mathrm{~A}$} \\
\hline TOM-584 & $1,50 \mathrm{a}$ & $2,44 \mathrm{~b}$ & $2,66 \mathrm{c}$ & \multicolumn{2}{|l|}{$2,88 \mathrm{~B}$} \\
\hline BPX-370E-30-380-68-6 (=Alto 1) & 1,16 a & $1,66 \mathrm{a}$ & $2,10 \mathrm{~b}$ & \multicolumn{2}{|l|}{$1,88 \mathrm{a}$} \\
\hline BPX-370E-30-380-68-8 (=Alto 2) & $1,16 \mathrm{a}$ & $1,66 \mathrm{a}$ & $2,22 \mathrm{~b}$ & \multicolumn{2}{|l|}{$2,00 \mathrm{a}$} \\
\hline BPX-370E-30-275-11-7 (=Alto 3) & 0,83 a & 1,66 a & $2,00 \mathrm{~b}$ & \multicolumn{2}{|l|}{$2,00 \mathrm{a}$} \\
\hline BPX-370E-30-275-11-8 (=Alto 4) & $1,16 \mathrm{a}$ & $1,33 \mathrm{a}$ & $2,22 \mathrm{~b}$ & \multicolumn{2}{|l|}{$1,88 \mathrm{a}$} \\
\hline BPX-370E-30-380-27-7 (=Baixo 1) & $1,50 \mathrm{a}$ & $2,00 \mathrm{~b}$ & $2,55 \mathrm{c}$ & \multicolumn{2}{|l|}{$2,66 \mathrm{~b}$} \\
\hline BPX-370E-25-271-29-2 (=Baixo 2) & $1,83 \mathrm{a}$ & $2,33 \mathrm{~b}$ & $2,66 \mathrm{c}$ & $3,10 \mathrm{~b}$ & \\
\hline Contrastes & & & ivas & & \\
\hline & $20 \mathrm{~d}$. a.i. & 30 d. a.i. & 40 d. a.i. & 50 d. a. & a.i. \\
\hline TOM-584 vs LA-716 & $0,83 *$ & $1,22 * *$ & $1,33 * *$ & $1,77 *$ & $* *$ \\
\hline $\begin{array}{l}\text { Genótipos com alto teor vs genótipos com } \\
\text { baixo teor }\end{array}$ & $-0,63 * *$ & $-0,71 * *$ & $-0,64 * *$ & $-1,10 *$ & $* *$ \\
\hline LA-716 vs genótipos com alto teor & $-0,41$ ns & $-0,36 \mathrm{~ns}$ & $-0,80 * *$ & $-0,83 *$ & \\
\hline LA-716 vs BPX-370E-30-380-68-6 & $-0,50$ ns & $-0,44^{\mathrm{ns}}$ & $-0,77 * *$ & $-0,77^{\mathrm{ns}}$ & \\
\hline LA-716 vs BPX-370E-30-275-11-8 & $-0,50$ ns & $-0,11$ ns & $-0,88 * *$ & $-0,77^{\mathrm{ns}}$ & \\
\hline Genótipos $\mathrm{F}_{3} \mathrm{RC}_{2}$ com alto teor vs & & & & & \\
\hline Genótipos com baixo teor & $-0,50 *$ & $-0,61 * *$ & $-0,47 * *$ & $-0,88 *$ & $* *$ \\
\hline TOM-584 vs genótipos com baixo teor & $-0,16^{\mathrm{ns}}$ & $-0,28$ ns & $0,05^{\mathrm{ns}}$ & 0,0 ns & \\
\hline Correlações (r): & & & & & \\
\hline (acilaçúcares vs níveis de dano) & $-0,86 * *$ & $-0,87 * *$ & $-0,84 * *$ & $-0,91 * *$ & \\
\hline
\end{tabular}


Tabela 2 - Notas médias de lesões nos folíolos e porcentagem de folíolos atacados pela traça Tuta absoluta, suas correlações e estimativas de contrastes de interesse de 8 genótipos de tomateiro selecionados para teores extremos de acilaçúcares. UFLA, Lavras, MG, 2004

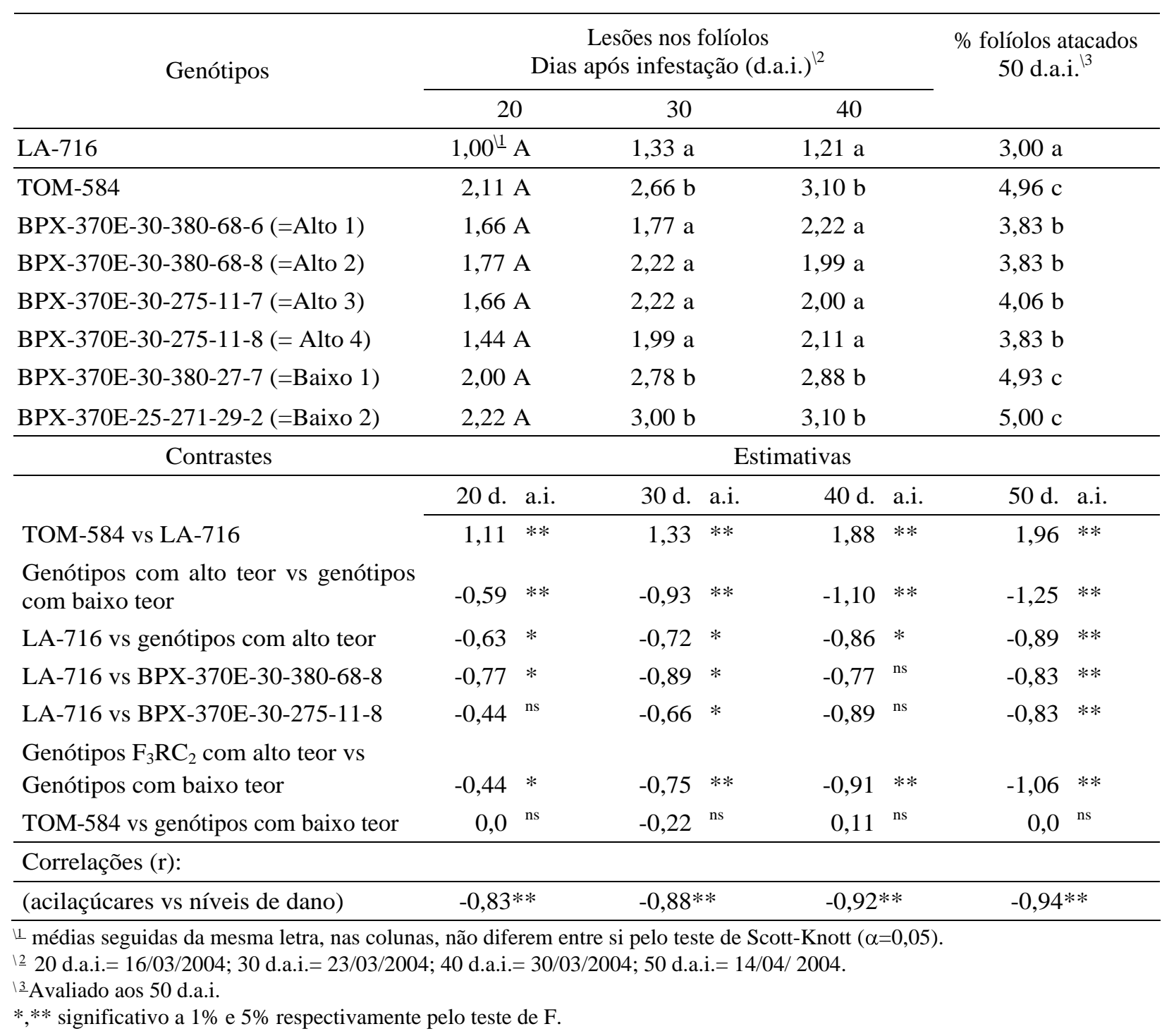

Os genótipos da geração $\mathrm{F}_{3} \mathrm{RC}_{2}$, com alto teor de acilaçúcares mostraram, por outro lado, notas para danos nas plantas e notas de lesões nos folíolos significativamente menores do que as apresentadas pela testemunha suscetível TOM-584 (Tabelas 1 e 2) ou do que as dos genótipos BPX-370E-30-380-27-7 e BPX-370E-25271-29-2, selecionados para baixo teor de acilaçúcares nos folíolos. Todos os genótipos com alto teor de acilaçúcares apresentaram também menor porcentagem de folíolos atacados do que a testemunha TOM-584 ou os genótipos selecionados para baixo teor.
Por sua vez, os genótipos selecionados para baixos teores de acilaçúcares, a partir da segunda época de avaliação apresentaram comportamento semelhante ao genitor recorrente TOM-584, com baixo teor de acilaçúcares nos folíolos, tanto para danos nas plantas (Tabela 1) quanto para lesões nos folíolos ou porcentagem de folíolos atacados (Tabela 2).

Com o avanço da infestação da traça, o efeito do aleloquímico nos folíolos mostrou-se mais evidente na resistência. Aos 50 dias após a infestação, os valores das médias dos genótipos com alto teor de acilaçúcares não 
diferiram para danos nas plantas e lesões nos folíolos, respectivamente (Tabelas 1 e 2).

As estimativas dos constrastes de interesse para a característica danos nas plantas mostraram que houve diferença significativa entre LA-716 e TOM-584 e entre os genótipos selecionados para alto teor de acilaçúcares e os de baixo teor. Por outro lado, não houve diferença significativa entre os dois genótipos selecionados para alto teor de acilaçúcares da geração $\mathrm{F}_{3} \mathrm{RC}_{2}$ e LA-716 na maioria das avaliações. Em outro contraste de interesse, todos os genótipos $\mathrm{F}_{3} \mathrm{RC}_{2}$ de alto teor de acilaçúcares apresentaram notas de danos significativamente inferiores, quando comparados com os genótipos de baixo teor em todas as avaliações. Para a característica lesões nos folíolos, os resultados dos contrastes foram semelhantes aos da característica danos nas plantas, somente havendo diferença entre eles quanto à diferença significativa nas estimativas do contraste entre o genótipo LA-716 e os genótipos $\mathrm{F}_{3} \mathrm{RC}_{2}$ selecionados para altos teores de acilaçúcares ao longo das avaliações. Por outro lado, as estimativas dos contrastes entre LA-716 e dois genótipos com altos teores, na avaliação de 40 d.a.i. não foram significativas.

Para a característica porcentagem de folíolos atacados, avaliados no final do experimento, foram obtidas estimativas altamente significativas entre o genótipo LA716 e os genótipos $\mathrm{F}_{3} \mathrm{RC}_{2}$ de altos teores de acilaçúcares e entre estes e os genótipos de baixos teores. Esses resultados evidenciaram três grupos distintos significativamente quanto à porcentagem de folíolos atacados.

As correlações entre os teores de acilaçúcares nos folíolos e os danos causados pela traça do tomateiro foram significativamente negativas e altas, aumentando em valor absoluto ao longo do tempo de exposição ao inseto, para todas as características avaliadas (Tabelas 1 e 2), confirmando a associação entre altos teores de acilaçúcares e resistência à traça do tomateiro.

Estes dados mostram haver uma efetiva associação entre o teor dos acilaçúcares e o nível de danos, permitindo que uma seleção indireta para plantas resistentes à traça do tomateiro possa ser realizada apenas avaliando-se o teor de acilaçúcares pelo método colorimétrico (RESENDE et al., 2002).

No experimento com ácaro, os genótipos $\mathrm{F}_{3} \mathrm{RC}_{2}$, selecionados para alto teor de acilaçúcares, em média, promoveram redução significativa nas distâncias percorridas pelos ácaros sobre a superfície do folíolo em relação aos genótipos selecionados para baixo teor aos
20, 40 e 60 minutos, conforme mostrado pelas médias das distâncias percorridas pelos ácaros (Tabela 5). Entre os genótipos, os que apresentaram alto teor de acilaçúcares nos folíolos destacam-se por demonstrar maior eficiência em repelir o caminhamento dos ácaros, não diferindo significativamente, pelo teste de Scott-Knott $(\mathrm{a}=0,05)$, do acesso selvagem LA-716, utilizado como fonte de resistência. Isso indica que a seleção de plantas com alto teor de acilaçúcares foi eficiente, pois elas se comportaram de forma semelhante ao genitor LA-716 quanto à repelência ao ácaro Tetranychus evansi. Por outro lado, os genótipos selecionados para baixo teor de acilaçúcares comportaramse sempre de maneira comparável à testemunha susceptível TOM-584.

As magnitudes das correlações analisadas (Tabela 3) confirmam a associação entre alto teor do aleloquímico e a repelência aos ácaros. Correlações negativas similares também foram relatadas para a repelência a ácaros determinada por outros aleloquímicos: 2-tridecanona (ARAGÃO, 1998; GONÇALVES et al., 1998) e zingibereno (um sesquiterpeno) (MALUF et al., 2001).

Os contrastes entre os genótipos $\mathrm{F}_{3} \mathrm{RC}_{2}$ com alto teor vs. genótipos com baixo teor de acilaçúcares quanto às distâncias médias percorridas pelos ácaros foram positivas e significativas, indicando que, em média, a seleção dos genótipos com base no teor de acilaçúcares nos folíolos foi eficiente na repelência ao ácaro (Tabela 3). Além disso, os genótipos $\mathrm{F}_{3} \mathrm{RC}_{2}$ quando foram contrastados com LA-716 não apresentaram valores diferentes significativos em nenhuma das avaliações. Outros contrastes de interesse, 'TOM-584 vs LA-716' e 'genótipos com altos teores de acilaçúcares vs genótipos com baixos teores', apresentaram diferenças significativas e os contrastes entre 'TOM-584 vs genótipos de baixo teor' não foram significativos ao longo das avaliações.

Os valores da correlação entre a concentração de acilaçúcares nos folíolos dos genótipos contrastantes selecionados na geração $\mathrm{F}_{3} \mathrm{RC}_{2} \mathrm{e}$ as distâncias percorridas pelo ácaro Tetranychus evansi demonstraram que as distâncias percorridas pelos ácaros, sobre a superfície dos folíolos, após 20, 40 e 60 minutos foram altas, negativas e significativas demonstrando que, quanto mais alto o teor de acilaçúcares presente no genótipo, menor é a distância percorrida pelos ácaros em seus folíolos (Tabela 3). O aumento na repelência ao ácaro foi uma resposta indireta à seleção para alto teor de acilaçúcares, nos genótipos de tomateiros selecionados.

As estimativas do contraste 'LA-716 vs genótipos de alto teor' não-significativas, indica que a seleção de 
Tabela 3 - Teores de acilaçúcares nos folíolos, distâncias médias percorridas pelos ácaros na superfície dos folíolos de 11 genótipos de tomateiro. UFLA, Lavras, MG, 2005.

\begin{tabular}{|c|c|c|c|c|}
\hline \multirow[t]{2}{*}{ Genótipos } & \multirow{2}{*}{ 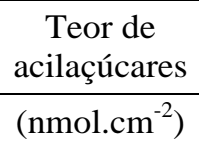 } & \multicolumn{3}{|c|}{$\begin{array}{l}\text { Distância percorrida pelo ácaro na superfície } \\
\text { do folíolo }(\mathrm{mm})\end{array}$} \\
\hline & & $20 \mathrm{~min}$ & $40 \min$ & $60 \min$ \\
\hline TOM-584 & $28,66 b^{11}$ & $6,2 \mathrm{~b}$ & $7,5 \mathrm{~b}$ & $7,9 \mathrm{~b}$ \\
\hline LA-716 & $64,03 \mathrm{~A}$ & $0,7 \mathrm{a}$ & $1,1 \mathrm{a}$ & $0,8 \mathrm{a}$ \\
\hline BPX-370E-25-271-30-5 (=Baixo1) & $32,19 \mathrm{~b}$ & $8,0 \mathrm{~b}$ & $9,5 \mathrm{~b}$ & $8,8 \mathrm{~b}$ \\
\hline BPX-370E-25-271-30-8 (=Baixo2) & $27,40 \mathrm{~b}$ & $9,4 \mathrm{~b}$ & $7,4 \mathrm{~b}$ & $9,9 \mathrm{~b}$ \\
\hline BPX-370E-25-271-79-7 (=Baixo 3) & $26,26 \mathrm{~b}$ & $6,0 \mathrm{~b}$ & $10,7 \mathrm{~b}$ & $11,5 \mathrm{~b}$ \\
\hline BPX-370E-30-275-70-2 (=Baixo 4) & $29,83 \mathrm{~b}$ & $6,0 \mathrm{~b}$ & $12,7 \mathrm{~b}$ & $13,0 \mathrm{~b}$ \\
\hline BPX-370E-30-275-70-9 (=Baixo 5) & $27,20 \mathrm{~b}$ & $11,2 \mathrm{~b}$ & $13,0 \mathrm{~b}$ & $13,0 \mathrm{~B}$ \\
\hline BPX-370E-30-380-68-6 (=Alto 1) & $55,65 \mathrm{a}$ & $4,0 \mathrm{a}$ & $4,0 \mathrm{a}$ & $3,7 \mathrm{a}$ \\
\hline BPX-370E-30-380-68-8 (=Alto 2) & 59,16 a & $2,5 \mathrm{a}$ & $4,0 \mathrm{a}$ & $4,2 \mathrm{a}$ \\
\hline BPX-370E-30-275-11-7 (=Alto 3) & 55,98 a & $2,9 \mathrm{a}$ & $3,6 \mathrm{a}$ & $3,8 \mathrm{a}$ \\
\hline BPX-370E-30-275-11-8 (=Alto 4) & 57,36 a & $4,1 \mathrm{a}$ & $4,8 \mathrm{a}$ & $4,6 \mathrm{a}$ \\
\hline \multirow[t]{2}{*}{ Contrastes } & \multicolumn{4}{|c|}{ Estimativas } \\
\hline & $20 \mathrm{~min}$ & $40 \mathrm{~min}$ & \multicolumn{2}{|c|}{$60 \mathrm{~min}$} \\
\hline TOM-584 vs LA-716 & $0,55 *$ & $0,64 *$ & 0,71 & $*$ \\
\hline $\begin{array}{l}\text { Genótipos com alto teor vs genótipos com } \\
\text { baixo teor }\end{array}$ & $-0,53 * *$ & $-0,70 * *$ & $-0,77$ & $* *$ \\
\hline LA-716 vs genótipos com alto teor & $-0,26^{\mathrm{ns}}$ & $-0,29$ ns & $-0,33$ & ns \\
\hline $\begin{array}{l}\text { Genótipos } \mathrm{F}_{3} \mathrm{RC}_{2} \text { com alto teor vs genótipos } \\
\text { com baixo teor }\end{array}$ & $-0,44 * *$ & $-0,60 * *$ & $-0,66$ & $* *$ \\
\hline TOM-584 vs genótipos com baixo teor & $-0,18$ ns & $-0,31$ ns & $-0,33$ & ns \\
\hline \multicolumn{5}{|l|}{ Correlações (r): } \\
\hline (acilaçúcares vs distâncias percorridas) & $-0,85 * *$ & $-0,88 * *$ & \multicolumn{2}{|c|}{$-0,92 * *$} \\
\hline
\end{tabular}

1 médias seguidas da mesma letra, nas colunas, não diferem entre si pelo teste de Scott-Knott $(\alpha=0,05)$.

$*$,** significativo a $1 \%$ e $5 \%$ respectivamente pelo teste de $\mathrm{F}$.

plantas com alto teor de acilaçúcares foi eficiente, pois elas se comportaram de forma semelhante à testemunha resistente LA-716, quanto à repelência ao ácaro Tetranychus evansi. Além disso, as estimativas dos contrastes entre genótipos de alto teor vs genótipos de baixo teor e genótipos $\mathrm{F}_{3} \mathrm{RC}_{2}$ com alto teor vs genótipos com baixo teor foram negativas, pois a distância percorrida no primeiro caso foi menor, e altamente significativas, ratificando a eficiência de seleção indireta de altos teores de acilaçúcares para resistência a ácaros.

Outros contrastes de interesse foram 'TOM-584 vs LA-716' e 'TOM-584 vs genótipos com baixos teores de acilaçúcares', sendo que o primeiro apresentou estimativas positivas e significativas, indicando que as distâncias percorridas pelos ácaros foram significativamente maiores do que no LA-716. No segundo contraste, as estimativas não foram significativas, indicando que as distâncias percorridas pelos ácaros não variaram significativamente entre os genótipos com baixos teores de acilaçúcares, utilizados no bioteste.

A seleção de genótipos, com teores contrastantes de acilaçúcares, foi eficiente em gerações avançadas de retrocruzamentos.

O método de seleção indireta, baseada no teor de acilaçúcares, foi eficiente para obtenção de plantas resistentes à traça do tomateiro (Tuta absoluta).

A seleção indireta, em populações segregantes derivadas do cruzamento interespecífico TOM-584 x LA- 
716, para elevado teor de acilaçúcares nos folíolos, permite eficientemente a obtenção de plantas resistentes ao ácaro Tetranychus evansi.

As plantas BPX-370E-30-380-68-8 e BPX-370E-30275-11-8, foram superiores nas avaliações de resistência à artrópodos-pragas e apresentaram os maiores teores de acilaçúcares das plantas da geração $\mathrm{F}_{3} \mathrm{RC}_{2}$. Essas plantas devem ser utilizadas em novos retrocruzamentos em continuidade ao programa de melhoramento.

\section{AGRADECIMENTOS}

Às instituições que apoiaram este projeto de pesquisa: FAPEMIG (Fundação de Amparo à Pesquisa do Estado de Minas Gerais), CNPq, CAPES/MEC, FAEPE, FUNDECC, UFLA e HortiAgro Sementes Ltda.

\section{REFERÊNCIAS BIBLIOGRÁFICAS}

ARAGÃO, C. A. Tricomas foliares associados à resistência ao ácaro rajado em linhagens de tomateiro com alto teor de 2-tridecanona nos folíolos. 1998. 71 p. Dissertação (Mestrado em Genética e Melhoramento de Plantas) Universidade Federal de Lavras, Lavras, 1998.

AZEVEDO, S. M.; MALUF, W. R.; FARIA, M. V.; OLIVEIRA, A. C. B.; RIBEIRO, C. A.; GONÇALVESGERVÁSIO, R. C.; SANTA-CECÍLIA, L. V. C. Resistência à traça (Tuta absoluta) em genótipos de tomateiro com diferentes teores de sesquiterpenos nos folíolos. In: CONGRESSO BRASILEIRO DE OLERICULTURA, 39., 1999, Tubarão. Resumo... Tubarão: SOB, 1999. 38 p.

BARBOSA, L. V. Controle genético e mecanismos de resistência em Lycopersicon spp à traça do tomateiro [Scrobipalpuloides absoluta (Meyrick, 1917) (Lep. Gelechiidae)]. 1994. 71 f. Dissertação (Mestrado em Genética e Melhoramento de Plantas) - Escola Superior de Agricultura de Lavras, Lavras, 1994.

BARBOSA, S.; FRANÇA, F. H. As pragas do tomateiro e seu controle. Informe Agropecuário, Belo Horizonte, v. 6, n. 66, p. $37-40$, jun. 1980 .

BARBOSA, V.; SILVEIRA NETO, J. M. Controle químico de Scrobpalpuloide absoluta (Meyrick) em tomateiro destinado ao processo industrial em São Paulo. In: CONGRESSO BRASILEIRO DE ENTOMOLOGIA, 8., 1984, Brasília, DF. Resumos... Brasília, DF: SEB, 1984. p. 125.

CAMPOS, G. A. Inter-relações entre teor de zingibereno, tipos de tricomas foliares e resistência a ácaros
Tetranychus evanci em tomateiro. 1999. 65 p. Dissertação (Mestrado em Fitotecnia) - Universidade Federal de Lavras, Lavras, 1999.

FILGUEIRA, F. A. R. Novo manual de olericultura: agrotecnologia moderna na produção e comercialização de hortaliças. Viçosa: UFV, 2000. 402 p.

FLECHTMANN, C. H. W. Ácaros de importância agrícola. 6. ed. São Paulo: Nobel, 1989. 189 p.

FLECHTMANN, C. H. W.; BAKER, E. W. A preliminary report on the Trenychidae (Acarina) of Brazil. Annals of on Entomological Society of America, Maryland, v. 63, n. 1, p. 153-163, Jan. 1970.

FREITAS, J. A. Resistência genética do tomateiro lycopersicon sp. À mosca branca Bemisia spp. Mediada por Zingibereno contida em tricomas glandulares. 1999. 93 p. Tese (Doutorado em Genética e Melhoramento de Plantas) - Universidade Federal de Lavras, Lavras, 1999.

GOFFREDA, J. C.; MUTSHLER, M. A.; AVÉ, D. A.; TINGEY, W. M.; STEFFENS, J. C. Aphid deterrence by glucose esters in glandular trichome exudate of wild tomato, Lycopersicon pennellii. Journal of Chemical Ecology, New York, v. 15, n. 7, p. 2135-2147, May 1989.

GOFFREDA, J. C.; MUTSCHLER, M. A.; TINGER, W. M . Feeding behavior of potato aphid affected by glandular trichomes of wild tomato. Entomologia Experimentalis et Applicata, Dordrecht, v. 48, n. 3, p. 101-107, Aug. 1988.

GONÇALVES, M. I. F.; MALUF, W. R.; GOMES, L. A. A.; BARBOSA, L. V. Variation of 2-tridecanone level in tomato plant leaflets and resistence to two mites species (Tetranychus sp.). Euphytica, Wageningen, v. 104, n. 1, p. 33-38, May 1998.

GONÇALVES-GERVÁSIO, R. C. R. Aspectos biológicos e parasitismo de ovos de Tuta absoluta (Meyrick, 1917) (Lepidoptera: Gelechiidae) por Trichogramma pretiosum Riley, 1879 (Hymenoptera: Trichogrammatidae) em genótipos de tomateiro contrastantes quanto ao teor de 2tridecanona nos folíolos. 1998. 71 p. Dissertação (Mestrado em Entomologia) - Universidade Federal de Lavras, Lavras, 1998. 
LABORY, C. R. Repetibilidade, herdabilidade no sentido restrito e mecanismo de resistência do teor do aleloquímico 2- Tridecanona em Lycopersicon spp. À traça do tomateiro Scrobipalpuloides absoluta (Meyrick, 1917) Lepdoptera - Gelechidae. 1996. Dissertação (Mestrado em Genética e Melhoramento de Plantas) - Universidade Federal de Lavras, Lavras, 1996.

LENKE, C. A.; MUTSCHLER, M. A. Inheritance of glandular trichomes in crosses between Lycopersicon esculentum and Lycopersicon pennellii. Journal of the American Society Horticultural Science, Mount, v. 109, n. 6, p. $592-$ 596, Nov. 1984.

LOURENÇÃO, A. L.; NAGAI, H.; ZULLO, M. A. T. Fontes de resistência a Scrobipalpula absoluta (Meyrick, 1917) em tomateiro. Bragantia, Campinas, v. 43, n. 2, p. 569-577, 1984.

MALUF, W. R.; CAMPOS, G. A.; CARDOSO, M. G Relationships between trichome types and spider mite (Tetranychus evansi) repellence in tomatoes with respect to foliar zingiberene contents. Euphytica, Wageningen, v. 121, n. 1, p. 73-80, Oct. 2001.

PAMPLONA, A. M. S. R. Avaliação de genotipos de tomate Lycopersicon ssp. com diferentes concentrações de acilaçucares, quanto a resistencia a Bemisia tabaci (Gennadius, 1889) (Hemitera: Aleyrodidae). 2001. Dissertação (Mestrado em Entomologia) - Universidade Federal de Lavras, Lavras, 2001.
RESENDE, J. T. V. Resistência a artrópodos-pragas, mediada por acilaçúcares em tomateiros obtidos do cruzamento interespecífico de Lycopersicon esculentum Mill 'TOM-584' x Lycopersicon pennellii 'LA-716'. 2003. 91 p. Tese (Doutorado em Fitotecnia) - Universidade Federal de Lavras, Lavras, 2003.

RESENDE, J. T. V.; CARDOSO, M. G.; MALUF, W. R.; SANTOS, C. D.; GONÇALVES, L. D.; RESENDE, L. V.; NAVES, F. O. Método colorimétrico para quantificação de acilaçúcar em genótipos de tomateiro. Ciência e Agrotecnologia, Lavras, v. 26, n. 6, p. 1204-1208, nov./dez. 2002.

SILVA, F. E.; CASALI, V. W. D. Cultura do tomateiro. Viçosa: UFV, 1979. $33 \mathrm{p}$.

SOUZA, J. C. de; REIS, P. R. Traça do tomateiro: histórico, reconhecimento, biologia, prejuízo e controle. 3. ed. rev. e aum. Belo Horizonte: EPAMIG, 2000. 32 p. (Boletim técnico, 57).

TAMAI, M. A. Avaliação de fungos entomopatogênicos para o controle de Tetranychus urticae (Koch). 1997. 85 f. Dissertação (Mestrado em Entomologia) - Escola Superior de Agricultura Luiz de Queiroz, Piracicaba, 1997.

WESTON, P. A.; JOHNSON, D. A.; BURTON, H. T.; SNYDER, J. C. Trichome secretion composition, trichome densities and spider mite resistence of ten accessions of Lycopersicon hirsutum. Journal of American Society for Horticultural Science, Mount Vermon, v. 114, n. 3, p. 492498, May 1989. 